\title{
Carbon-containing Hydroxyapatite Obtained from Fish Bone as Low-cost Mesoporous Material for Methylene Blue Adsorption
}

\author{
Ratna Kusumawardani ${ }^{1}$, Mukhamad Nurhadi ${ }^{1 *}$, W. Wirhanuddin ${ }^{1}$, Rahmat Gunawan $^{2}$, \\ Hadi Nur ${ }^{3,4}$
}

${ }^{1}$ Department of Chemical Education, Universitas Mulawarman, Kampus Gunung Kelua, Samarinda, 75119, East Kalimantan, Indonesia

${ }^{2}$ Chemistry Department, Universitas Mulawarman, Kampus Gunung Kelua, Samarinda, 75119,

East Kalimantan, Indonesia

${ }^{3}$ Center for Sustainable Nanomaterials, Ibnu Sina Institute for Scientific and Industrial Research, Universiti

Teknologi Malaysia, Johor Bahru, 81310, Malaysia

${ }^{4}$ Central Laboratory of Minerals and Advanced Materials, Faculty of Mathematics and Natural Sciences, State

University of Malang, Indonesia

Received: $7^{\text {th }}$ July 2019; Revised: $13^{\text {th }}$ August 2019; Accepted: 20th August 2019;

Available online: 30th September 2019; Published regularly: December 2019

\section{Abstract}

The carbon-containing hydroxyapatite has been synthesized using the fish bone obtained from East Kalimantan, Indonesia. The synthesis was conducted at varying calcination temperature $\left(300-700{ }^{\circ} \mathrm{C}\right)$ and duration time $(1-5$ h). The carbon-containing hydroxyapatite were characterized by using Nitrogen adsorption-desorption, Fourier transform infrared spectroscopy, X-ray diffraction (XRD), Scanning electron microscopy (SEM), and Thermogravimetric analysis (TGA) and Differential thermal analysis (DTA). The carbon-containing hydroxyapatite nanoparticles consisted of the mesoporous structure with a specific surface area of $159 \mathrm{~m}^{2} \cdot \mathrm{g}^{-1}$ and pore size of $44 \AA$. The carbon-containing hydroxyapatite nanoparticles were utilized as the adsorbent for the removal of methylene blue by varying the contact time, initial dye concentration, $\mathrm{pH}$, adsorbent dosage and temperature. The maximum amount of adsorption capacity was $56.49 \mathrm{mg}$. ${ }^{-1}$. The adsorption was well fitted with the Langmuir adsorption model $\left(\mathrm{R}^{2} \sim 0.998\right)$ and the pseudo-second-order model. This indicated that the dye molecules were adsorbed on the surface-active site of carbon-containing hydroxyapatite via chemical binding, forming an adsorbate monolayer. Hence, the adsorption capability corresponds to the physical properties such as the surface area and pore volume of hydroxyapatite because the larger surface area consists of higher binding sites for the adsorption. Thermodynamic parameters, including the Gibbs free energy $(\Delta \mathrm{G})$, enthalpy $(\Delta \mathrm{H})$, and entropy $(\Delta \mathrm{S})$, indicated that the adsorption of methylene blue onto the carbon-containing hydroxyapatite nanoparticles was spontaneous. Thus, carbon-containing hydroxyapatite nanoparticles can be applied as a low-cost adsorbent for the treatment of industrial effluents that are contaminated with the methylene blue. Copyright (C) 2019 BCREC Group. All rights reserved

Keywords: Fish bone; Mesoporous material; Carbon-containing hydroxyapatite; Adsorption; Methylene blue

How to Cite: Kusumawardani, R., Nurhadi, M., Wirhanuddin, W., Gunawan, R., Nur, H. (2019). Carboncontaining Hydroxyapatite Obtained from Fish Bone as Low-cost Mesoporous Material for Methylene Blue Adsorption. Bulletin of Chemical Reaction Engineering \& Catalysis, 14(3): 660-671 (doi:10.9767/bcrec.14.3.5365.660671)

Permalink/DOI: https://doi.org/10.9767/bcrec.14.3.5365.660-671

\section{Introduction}

The effluents discharged from industries such as manufacturing of textile, paper, plastic,

* Corresponding Author.

E-mail: nurhadi1969@yahoo.co.id (W. Wirhanuddin); leather, food, printing and cotton mordant with tanning have caused the serious environmental pollution [1]. The synthetic dyes like methylene blue (MB) that is usually found in the industrial effluents are very toxic and carcinogenic to the aquatic living organisms, animal, and even human [2-5]. The removal of dyestuffs from indus- 
trial effluents using traditional way is challenging due to the high sensitivity to environmental factors, including the light and $\mathrm{pH}$ level. Nevertheless, the materials used could be difficult to be decomposed by bacteria or other living organisms, causing subsequent pollution. The methods to eliminate dyestuffs from effluents are known to be the biological treatment (fungal decolourization, microbial degradation, bioremediation), chemical methods (coagulation, electroflotation, electrokinetic coagulation, oxidation, irradiation) and physical methods (filtration, adsorption) [6]. Among that methods, adsorption technique has attracted much attention in recent years due to their efficiency in the purification and chemical recovery application [7].

Recently, many researchers attempt to find low-cost adsorbents to remove dyestuffs. For examples; The marine green alga Ulva lactuca as low cost adsorbent to remove methylene blue but only can be applied on low dye initial concentration[8]. The mesoporous bone char obtained by pyrolysis of animal bones effective to use as dye adsorbent but still in low dye concentration and small amount of dye solution (20 mL) [7]. The activated carbon prepared from cashew nut shell can be used to remove methylene blue but not costly to prepare it [9]. Carbon-containing bone hydroxyapatite obtained from tuna bone was good performance to adsorb dye but only suitable for congo red dye [1]. The activated carbon produced from tea (Cammellia sinensis) seed shell has high performance to adsorb methylene blue but no costly to prepare it [10], NaAlg-g-Poly(acrylic acidco-acryl amide/Clinoptilolite hydrogel nanocomposite can remove $99.47 \%$ methylene blue but the experiment still in low concentration of dye (25 mg.L $\mathrm{L}^{-1}$ ) [11]. The clay and pillared clays can be used as low cost adsorbent but not effective due to need a lot of adsorbent in experiment (0.2 $\mathrm{g}$ in $5 \mathrm{~mL}$ sample) [12,13]. The yellow passion fruit peel can be used as low cost adsorbent to remove methylene blue but need much time $(72 \mathrm{~h})$ to reach equilibrium [3] and the remove dyestuffs use Eichhornia crassipes as adsorbent is costly but only suitable to adsorb azo and anthraquinone [14,15].

Indonesia that consists of 17,505 islands with $70 \%$ territorial water was the largest archipelagic country in the world. In 2015, the fishery production has reached 14.79 million tons which have made Indonesia the top fishery production in the world after China. The fish bones become the main waste in the production. These fish bones are often dumped as wastes. Therefore, the conversion of wasted fish bones into adsorbent not only add considerable economic value but also provides a lowcost solution compared to the expensive commercialized adsorbent such as activated carbon. Previous research carbon-containing hydroxyapatite must be prepared by pyrolysis process in nitrogen atmosphere at high temperature $\left(900{ }^{\circ} \mathrm{C}\right)$ [16]. The objective of this work is to demonstrate the fish bones are used as the precursor to prepare carbon-containing hydroxyapatite by simple thermal activation: the powder of fish bones was carbonized directly in the furnace with varying temperature (300, 400, 500, 600, and $700{ }^{\circ} \mathrm{C}$ ) in air atmosphere for 2 hours. Carbonization process was also conducted at $500^{\circ} \mathrm{C}$ with duration time $1,2,3$, 4 , and $5 \mathrm{~h}$ that used to study the effect of time duration to the physical properties of carbonderivate fish bones. The adsorption capability was tested using the methylene blue dye solution. The adsorption properties and mechanism were evaluated using the kinetic equilibrium models and the thermodynamic studies.

\section{Materials and Methods}

\subsection{Materials}

The fish bones were collected from waste of many food companies in Samarinda, East Kalimantan, Indonesia. Sodium hydroxide pellets for analysis was purchased from Merck. Hydrochloric acid (37\%) was supplied by Merck. Methylene blue was purchased from Merck.

\subsection{Carbon-containing hydroxyapatite prepara-} tion

The fish bones were cleaned by washing using boiling water. The fish bones were then dried in an oven at $110{ }^{\circ} \mathrm{C}$ for 24 hours. Obtained dried bones were crushed and sieved to get a powder with the size of 100 mesh and was labelled as FB. The powder of fish bones was further calcined in a furnace at temperatures of $300,400,500,600$, and $700{ }^{\circ} \mathrm{C}$ for 2 hours. The powder obtained after calcination was labelled as CFB-X(Y), where $\mathrm{X}$ is the calcination temperature and $\mathrm{Y}$ is the duration of calcination. For instance, CFB-300(2) represents the sample that was obtained after calcination at $300{ }^{\circ} \mathrm{C}$ for $2 \mathrm{~h}$. To study the effect of time duration in calcination process, the powder of fish bones was calcined at $500{ }^{\circ} \mathrm{C}$ with time duration (1-5 h).

\subsection{Samples Characterization}

The surface properties of the samples were determined by $\mathrm{N}_{2}$ adsorption-desorption. Be- 

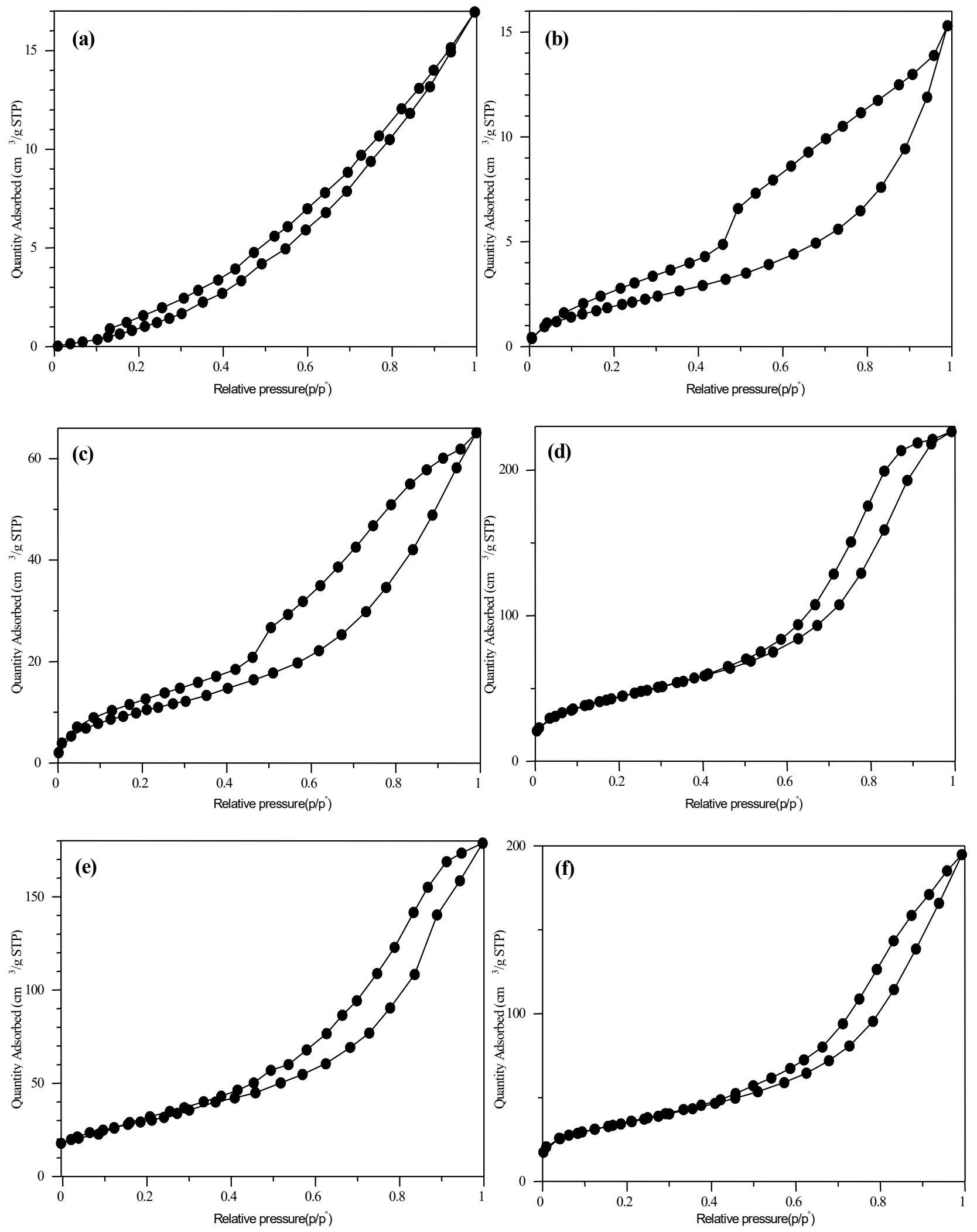

Figure 1. The effect of calcination temperature to the physisorption isotherms of (a) FB, (b) CFB300(2), (c) CFB-400(2), (d) CFB-500(2), (e) CFB-600(2) and (f) CFB-700(2). 
fore analysis, the samples were degassed at 150 ${ }^{\circ} \mathrm{C} . \mathrm{N}_{2}$ adsorption-desorption isotherms were determined at $77 \mathrm{~K}$ using a surface area analyzer Quantachrome instruments version 11.0. The BET (Brunauer Emmet-Teller) surface area was estimated over a relative pressure $\left(\mathrm{P} / \mathrm{P}_{0}\right)$ range of $0.05-0.30$. The pore size distribution was measured with the Barrett-JoynerHalenda (BJH) adsorption. The X-ray diffraction (XRD) of the sample was obtained in the $2 \theta$ range of $2^{\circ}$ to $65^{\circ}$ using Bruker AXS Advance $\mathrm{D} 8$ diffractometer with $\mathrm{Cu}-\mathrm{K} \alpha$ radiation at $40 \mathrm{kV}$ and $40 \mathrm{~mA}$. The functional groups of the sample were determined using the Perkin Elmer Fourier Transform Infrared at room temperature with a spectral resolution of $2 \mathrm{~cm}^{-1}$ and scan time of $10 \mathrm{~s}$. JEOL JSM-6701F Scanning Electron Microscopy (SEM) instrument with an accelerating voltage of $15 \mathrm{kV}$ was used to investigate the surface textures in the samples. The thermal stability of adsorbent was examined by using thermal gravimetric analysis (TGA), STA Linseis PT1600 instrument with

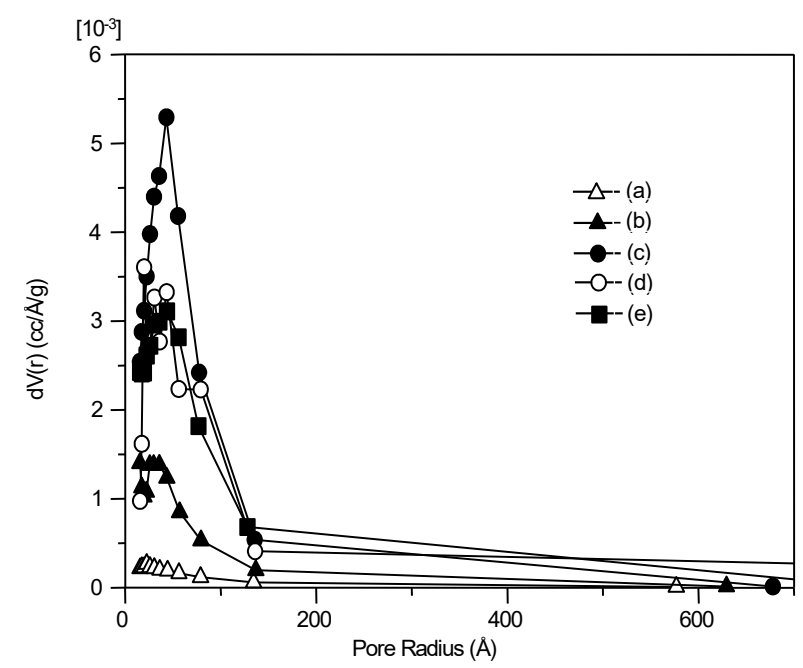

Figure 2. BJH pore size distribution of (a) CFB-300(2), (b) CFB-400(2), (c) CFB-500(2), (d) CFB-600(2) and (e) CFB-700(2). heat rate of $10^{\circ} \mathrm{C} \cdot \mathrm{min}^{-1}$ and target temperature $900{ }^{\circ} \mathrm{C}$.

\subsection{Adsorption Test}

Adsorption capability of samples were tested with methylene blue dye. The adsorbent $(0.25 \mathrm{~g})$ was inserted into a test tube containing $25 \mathrm{~mL}$ of methylene blue dye (100 mg. $\left.\mathrm{L}^{-1}\right)$. The experiment was carried out at different $\mathrm{pH}$ value, the initial concentration of dye, adsorbent dosage and temperatures to find out the optimum operating condition. The effect of $\mathrm{pH}$ was investigated in the $\mathrm{pH}$ range of 2.010.0 that was adjusted using $\mathrm{HCl}(0.1 \mathrm{M})$ and $\mathrm{NaOH}(0.1$ M). The initial concentration of methylene blue dye was set to be 50-1000 mg.L ${ }^{-1}$. Three different dosages of adsorbent were used, which are $62.5,125$, and $250 \mathrm{mg}$. The operating temperature was fixed at 30,40 , and $50{ }^{\circ} \mathrm{C}$. All adsorption tests were conducted under a stirring rate of $200 \mathrm{rpm}$. When the reaction was completed, the solution was filtered, and the residual dye concentration was analyzed using a UV-Vis spectrophotometer at $660 \mathrm{~nm}$.

The adsorption capacities $\left(q_{e}\right)$ is expressed as the dye adsorbed per gram of adsorbent (mg.g $\left.{ }^{-1}\right)$ and the adsorption efficiency (\%) of the adsorbent were calculated using equations below [17-19]:

$$
\begin{aligned}
& q_{e}=\frac{\left(C_{i}-C_{f}\right) \cdot V}{W} \\
& \text { Adsorption efficiency }(\%)=\frac{\left(C_{i}-C_{f}\right)}{C_{f}} \times 100 \%
\end{aligned}
$$

where $C_{i}$ is the initial concentration of dye (mg.L-1), $C_{f}$ is the dye concentration after adsorption time $t, V$ is the volume of dye solution $(\mathrm{mL})$, and $W$ is the adsorbent weight $(\mathrm{g})$.

Table 1. Physical properties of (a) FB, (b) CFB-300(2), (c) CFB-400(2), (d) CFB-500(2), (e) CFB-600(2) and (f) CFB-700(2).

\begin{tabular}{ccccc}
\hline Samples & $\begin{array}{c}\text { Pore Radius } \\
(\AA)\end{array}$ & $\begin{array}{c}\text { Pore Volume } \\
\left(\mathrm{cm}^{3} \cdot \mathrm{g}^{-1}\right)\end{array}$ & $\begin{array}{c}\text { Surface Area } \\
\left(\mathrm{m}^{2} \cdot \mathrm{g}^{-1}\right)\end{array}$ & $\begin{array}{c}\text { Micropore Area } \\
\left(\mathrm{m}^{2} \cdot \mathrm{g}^{-1}\right)\end{array}$ \\
\hline FB & 17.4 & 0.015 & 8.2 & 6.932 \\
CFB-300(2) & 59.6 & 0.023 & 7.9 & 0.000 \\
CFB-400(2) & 50.9 & 0.101 & 39.5 & 0.000 \\
CFB-500(2) & 44.1 & 0.350 & 158.8 & 0.000 \\
CFB-600(2) & 50.7 & 0.276 & 108.9 & 0.475 \\
CFB-700(2) & 48.5 & 0.301 & 124.2 & 0.000 \\
\hline
\end{tabular}



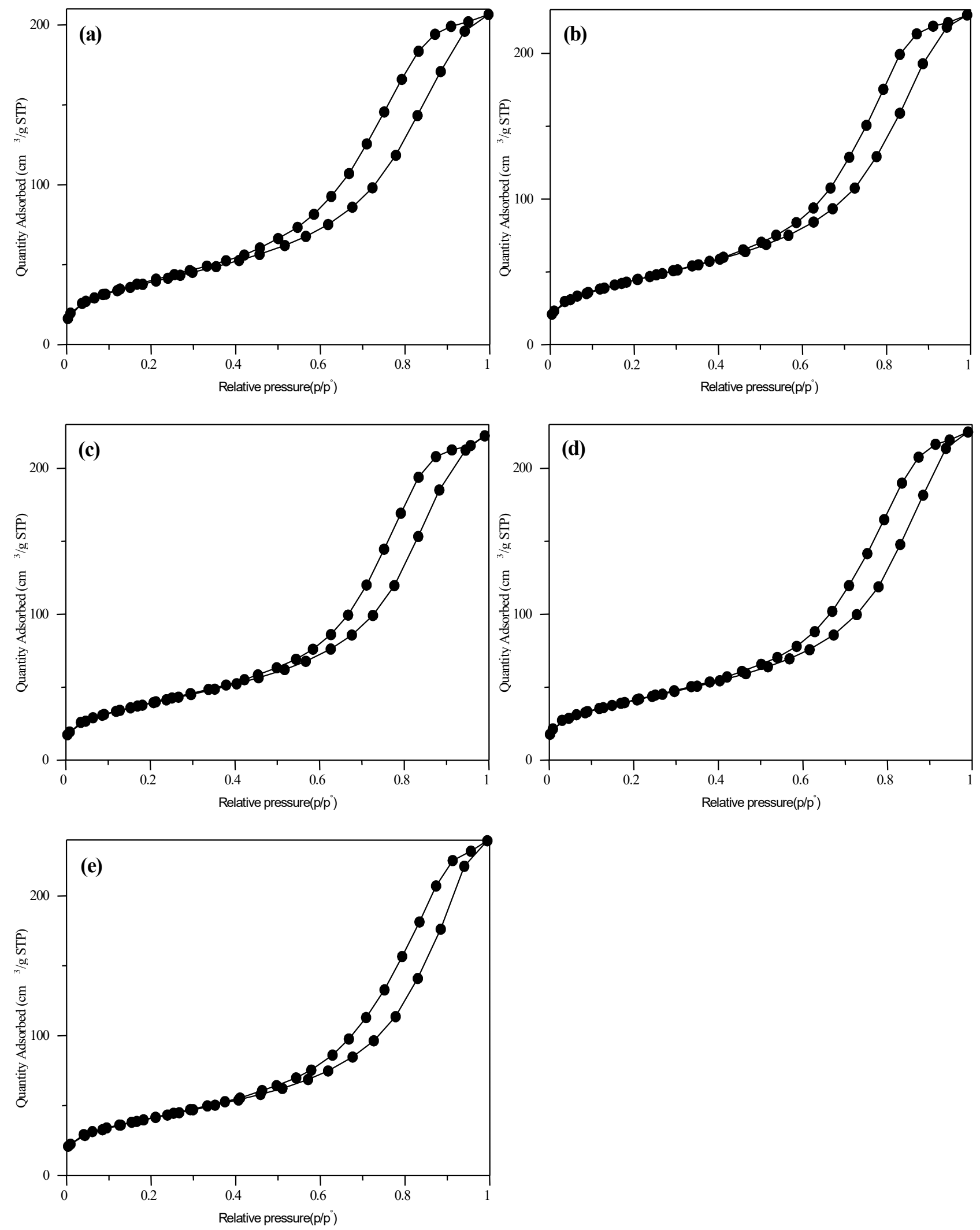

Figure 3. Effect of calcination duration to the isotherm models of (a) CFB-500(1), (b) CFB-500(2), (c) CFB-500(3), (d) CFB-500(4) and (e) CFB-500(5). 


\section{Results and discussion}

\subsection{Physical Properties}

The synthesis of carbon-containing hydroxyapatite was optimized from the aspect of calcination temperature and duration. Untreated FB was used as our main reference. In Figure 1(a), FB has a type III $\mathrm{N}_{2}$ adsorptiondesorption isotherm, indicating that FB is nonporous or macroporous. Upon calcination, the physical properties of FB changed significantly. The $\mathrm{N}_{2}$ adsorption-desorption isotherms type of CFB-300(2), CFB-400(2), CFB-500(2), CFB600(2) and CFB-700(2) become typical type IV patterns with clear hysteresis loops in the relative low-pressure range that indicates the presence of mesopores. The hysteresis loops of CFB300(2), CFB-400(2) and CFB-700(2) (Figure $1(\mathrm{a}-\mathrm{b})$ ) are type $\mathrm{H}_{3}$ which is the characteristic

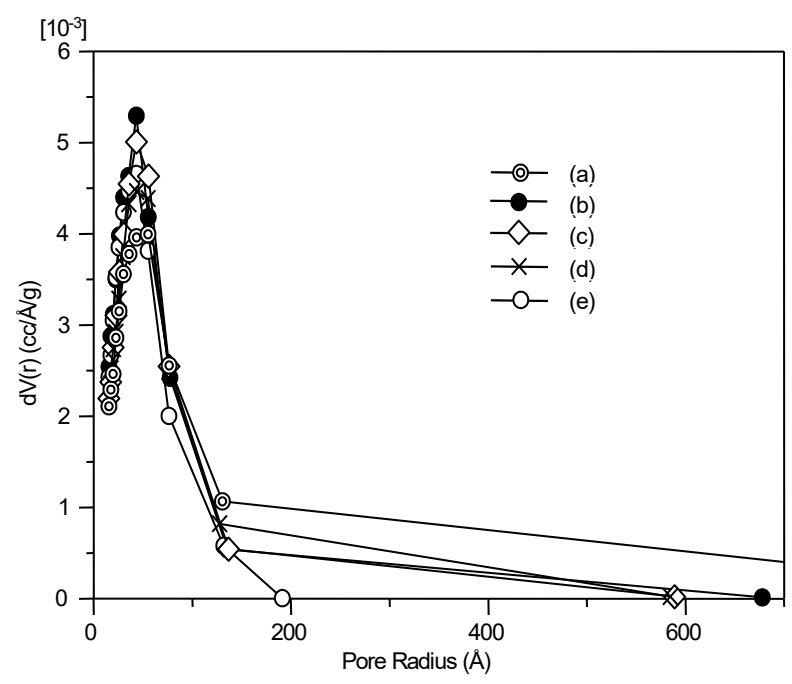

Figure 4. BJH pore size distribution (a) CFB500(1), (b) CFB-500(2), (c) CFB-500(3), (d) CFB500(4) and (e) CFB-500(5).

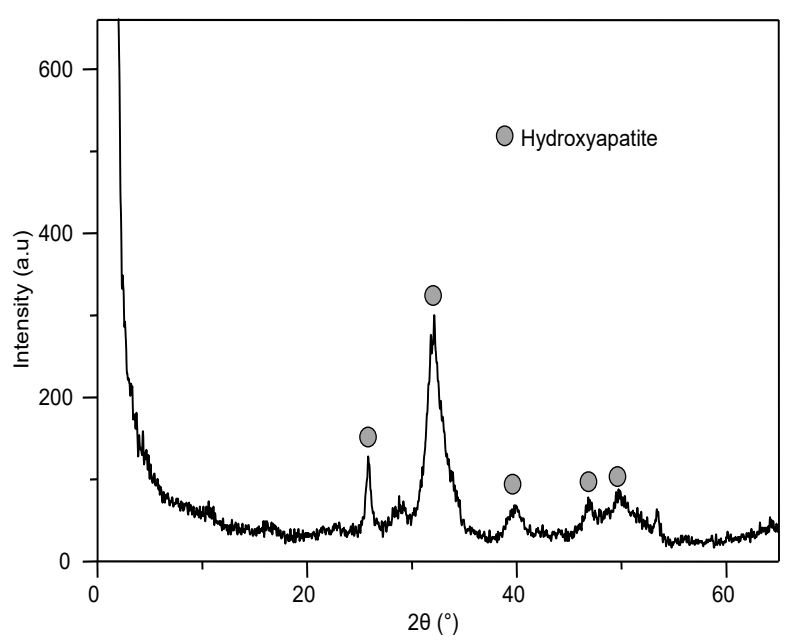

Figure 5. XRD pattern of CFB-500(2). signal for the solids consisting of aggregates or agglomerates of particles forming slit-shaped pores (plates or edged particles like cubes). On the other hands, the hysteresis loops type of CFB-500(2) and CFB-600(2) (Figure 1(c-d)) are type $\mathrm{H}_{1}$ which is often identified with porous materials exhibiting a narrow distribution of relatively uniform (cylindrical-like) pores. Both hysteresis loops are not different due to the amount carbon released from the samples during carbonization process from 500 to $600{ }^{\circ} \mathrm{C}$ were not influence to pore structure or network models attribute hysteresis (pore blocking or percolation). All the samples consisted of uniform mesopores (44.1-59.6 ̊) as shown in Figure 2. The physical properties of all samples were listed in Table 1. Overall, the calcination treatment not only increased the pore size but also the surface area of FB. The surface area increases from $\sim 8$ to $159 \mathrm{~m}^{2} \cdot \mathrm{g}^{-1}$ when calcination temperature reaches $500{ }^{\circ} \mathrm{C}$. The effect of calcination duration was further investigated using CFB-500. Figure 3 showed the $\mathrm{N}_{2}$ adsorption-desorption isotherms of CFB-500 synthesized from 1-5 hours. As the calcination duration increased, all the sample shows typical type IV patterns with the $\mathrm{H}_{1}$ hysteresis loops type. As shown in Figure 4, prolonging the calcination duration bring insignificant impact onto the physical properties of CFB-500. This phenomenon was caused the amount of carbon released from samples for a duration time of carbonization process (1-5 hours) not change pore structure. The pore size distribution is in a narrow range between 45.1-50.8 . Based on the data listed in both Table 1 and 2, calcination at $500{ }^{\circ} \mathrm{C}$ for 2 hours is the most optimum synthesis condition to obtain a CFB with high pore volume and surface area.

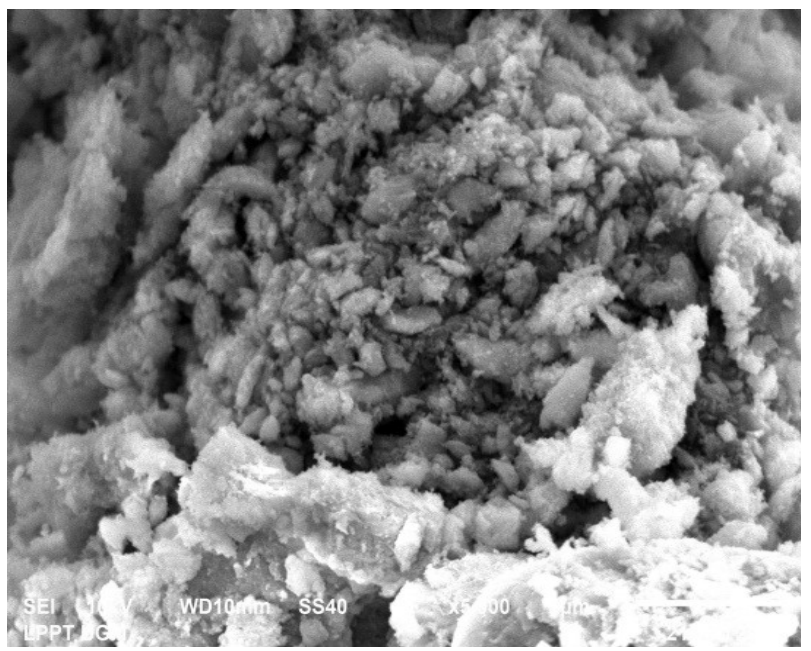

Figure 6. SEM micrograph of CFB-500(2). 
The XRD pattern of CFB-500(2) is depicted in Figure 5. The diffraction peaks at $2 \theta=25.9$, $31.8,46.8,49.6,53.4$, and 64.4 prove that CFB500 (2) was in the form of hydroxyapatite. The average size of hydroxyapatite is predicted using the Debye-Scherrer equation [7]:

$$
T=\frac{K \cdot \lambda}{\beta \cdot \cos \theta}
$$

where $T$ is the average of crystal size, $K$ is the shape factor (0.9), $\lambda$ is the X-ray wavelength $(0.15406 \mathrm{~nm}), \beta$ is the line broadening at full width at half maximum $(\mathrm{FWHM}=0.02783)$ on the $2 \theta=31.806$ scale in radians and $\theta$ is the Bragg angle of the peak in degrees. The average crystal size of hydroxyapatite was estimated to be $5.18 \mathrm{~nm}$. The morphology of CFB500 (2) was observed using scanning electron microscopy (SEM) as shown in Figure 6. The particles size of CFB-500(2) was observed to be much bigger compared to the result obtained using XRD. This indicated that the CFB-500(2) nanoparticles tend to aggregate to form bigger particles.

The chemical properties of CFB-500(2) was checked using FTIR. The FTIR spectrum in Figure 7 shows several strong peaks which are the characteristic bands of hydroxyapatite.

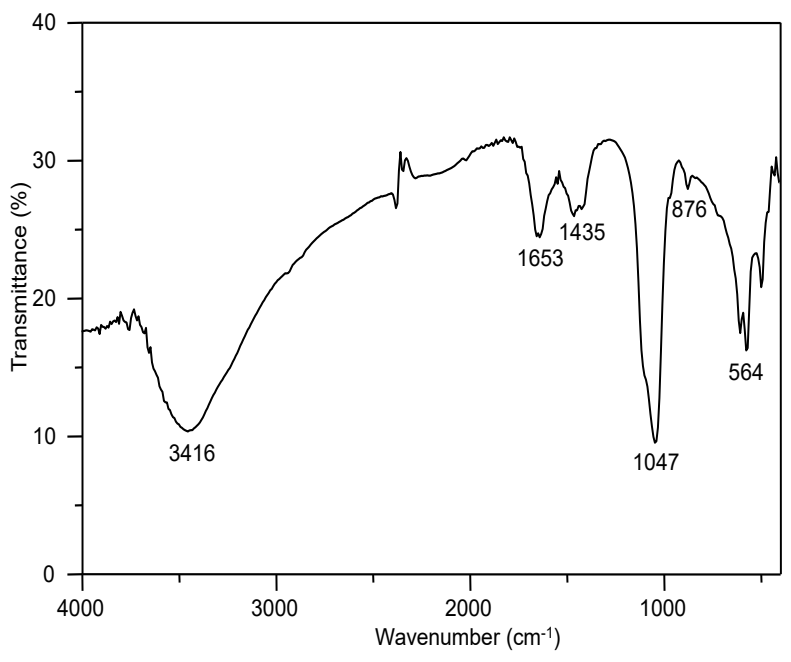

Figure 7. FTIR spectra of CFB-500(2).
The peaks located at $3416 \mathrm{~cm}^{-1}$ and $1653 \mathrm{~cm}^{-1}$ are associated to the $\mathrm{O}-\mathrm{H}$ stretching. The absorption bands at $1435 \mathrm{~cm}^{-1}$ and $876 \mathrm{~cm}^{-1}$ are $\mathrm{C}-\mathrm{O}$ stretching vibration which correlated to carbonate ion $\left(\mathrm{CO}_{3}{ }^{2}\right)$ substitution in the crystal lattice. Whilst, the absorption bands at 1047 $\mathrm{cm}^{-1}$ and $564 \mathrm{~cm}^{-1}$ are assigned to the $\mathrm{P}-\mathrm{O}$ stretching vibration in phosphate ion $\left(\mathrm{PO}_{4}{ }^{3}\right)$ groups [20]. CFB-500(2) was also analyzed using TG. Based on the thermogram in Figure 8, the CFB-500(2) experiences two steps of weight losses. TGA displays a slight weight loss $(\sim$ $9.5 \%)$ at the temperature below $200{ }^{\circ} \mathrm{C}$, indicating the evaporation of moisture from the CFB-500(2) surface. In the temperature range of $200-550{ }^{\circ} \mathrm{C}$, another weight loss of about $11.9 \%$ is observed, which can be associated with the decomposition of the organic group.

\subsection{Methylene Blue Dye Adsorption}

CFB-500(2) was used for the methylene blue adsorption test. Figure 9 shows the adsorption of methylene blue at $30^{\circ} \mathrm{C}$. The initial concentration of methylene blue was $100 \mathrm{mg} \mathrm{L}^{-1}$ and the $\mathrm{pH}$ of solution was 6.9. The removal rate of methylene blue increases drastically in the first $10 \mathrm{~min}$ and thereafter reaches equilibrium

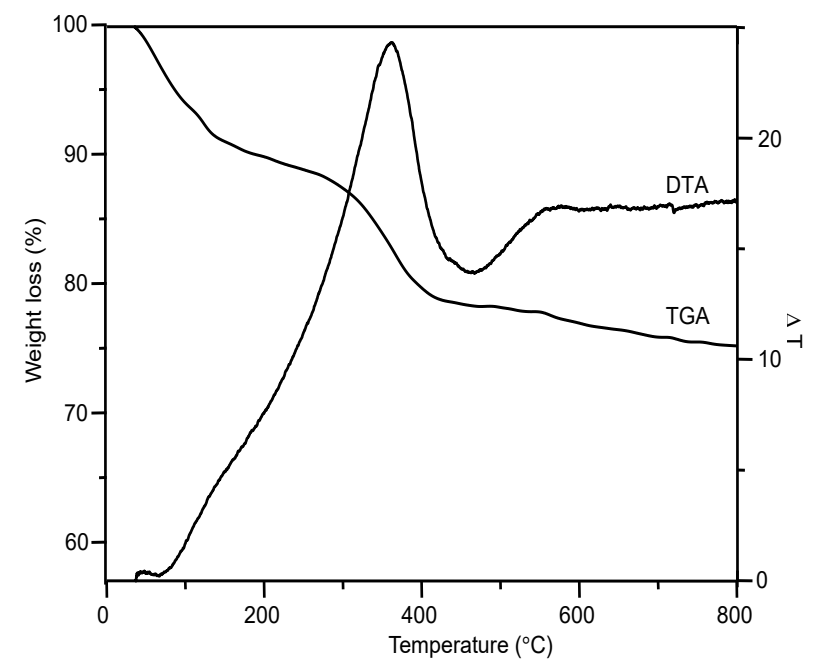

Figure 8. TGA and DTA curves of CFB-500(2).

Table 2. Physical properties of (a) CFB-500(1), (b) CFB-500(2), (c) CFB-500(3), (d) CFB-500(4) and (e) CFB-500(5).

\begin{tabular}{ccccc}
\hline Samples & $\begin{array}{c}\text { Pore radius } \\
(\AA)\end{array}$ & $\begin{array}{c}\text { Pore volume } \\
\left(\mathrm{cm}^{3} \cdot \mathrm{g}^{-1}\right)\end{array}$ & $\begin{array}{c}\text { Surface area } \\
\left(\mathrm{m}^{2} \cdot \mathrm{g}^{-1}\right)\end{array}$ & $\begin{array}{c}\text { Micropore area } \\
\left(\mathrm{m}^{2} \cdot \mathrm{g}^{-1}\right)\end{array}$ \\
\hline CFB-500(1) & 45.3 & 0.319 & 141.0 & 0.000 \\
CFB-500(2) & 44.1 & 0.350 & 158.8 & 0.000 \\
CFB-500(3) & 48.9 & 0.343 & 140.5 & 0.000 \\
CFB-500(4) & 47.5 & 0.348 & 146.3 & 0.000 \\
CFB-500(5) & 50.8 & 0.370 & 145.9 & 0.000 \\
\hline
\end{tabular}


in about $30 \mathrm{~min}$. The removal of methylene blue remains constant up to $720 \mathrm{~min}$. It can be assumed that the adsorption process has reached a quasi-equilibrium stage in the first 30 min. Figure 10 shows the initial dye concentration versus the quantity of dye adsorbed $q_{e}$. The quantity of dye adsorbed increases from 4.98 to $57.01 \mathrm{mg} \cdot \mathrm{g}^{-1}$ when the initial concentration increases from 50 to $1000 \mathrm{mg} . \mathrm{L}^{-1}$. However, the dye removal percentage decreases from 99.06 to $57.01 \%$. As can be seen, the efficiency of CFB-500(2) drops when the concentration of methylene blue exceeds $500 \mathrm{mg} \cdot \mathrm{L}^{-1}$. At dye concentration below $500 \mathrm{mg} . \mathrm{L}^{-1}$, the number of active sites on the surface CFB-500(2) is still sufficient for the adsorption of dye molecules. However, at high initial concentration, the

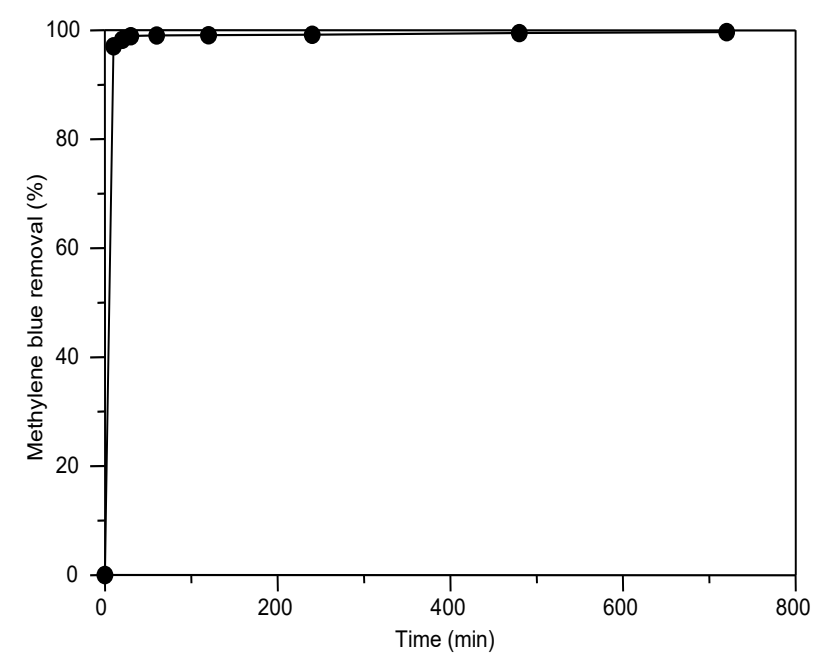

Figure 9. Effect of contact time on methylene blue dye removal. Conditions: $(\mathrm{pH}: 6.9$, MB: 100 $\mathrm{mg} \cdot \mathrm{L}^{-1}$, weight adsorbent: $250 \mathrm{mg}$, at $30^{\circ} \mathrm{C}$ ).

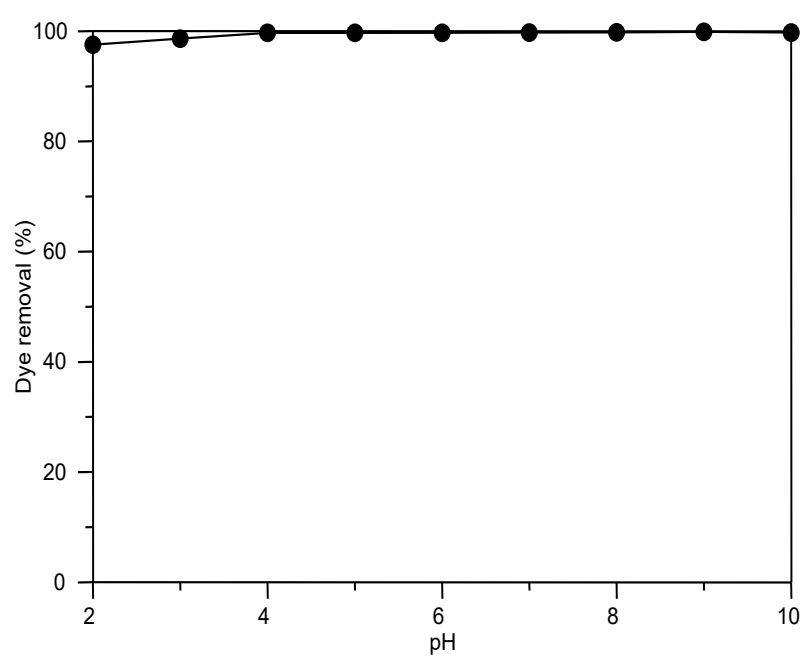

Figure 11. Effect of $\mathrm{pH}$ on methylene blue removal. Conditions: (MB: $100 \mathrm{mg} . \mathrm{L}^{-1}$, weight adsorbent: $250 \mathrm{mg}$, at $30^{\circ} \mathrm{C}$ ). quantity of dye adsorbed per unit weight of adsorbent $\left(q_{t}\right)$ was also high. Adsorption process at low dye concentration, the value of the percentage (\%) of dye removal opposite with the amount of dye removal capacity $\left(q_{t}, \mathrm{mg}^{\mathrm{g}} \mathrm{g}^{-1}\right)$. This phenomenon was caused at the low concentration for the same amount of adsorbent in the experiment the percentage of dye removal becomes high $(\sim 100 \%)$ due to almost all the dye concentration totally was absorbed. Otherwise, the amount of dye removal $\left(q_{t}\right)$ becomes low due to at low concentration the number of dye adsorbed (mg.g $\left.{ }^{-1}\right)$ also small for the same amount of adsorbent. Along with the increasing of the initial of dye concentration the percentage of dye removal becomes low due to the increase of the dye concentration adsorbed was

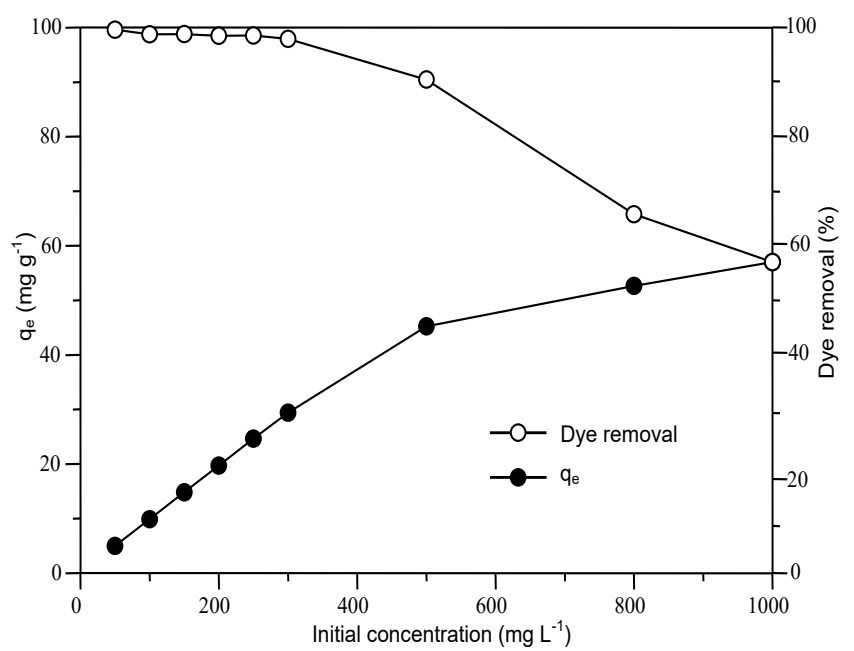

Figure 10. Effect initial methylene blue dye concentration. Conditions: (pH: 6.9, MB: 50-1000 mg. $\mathrm{L}^{-1}$, weight adsorbent: $250 \mathrm{mg}$, at $30^{\circ} \mathrm{C}$ ).

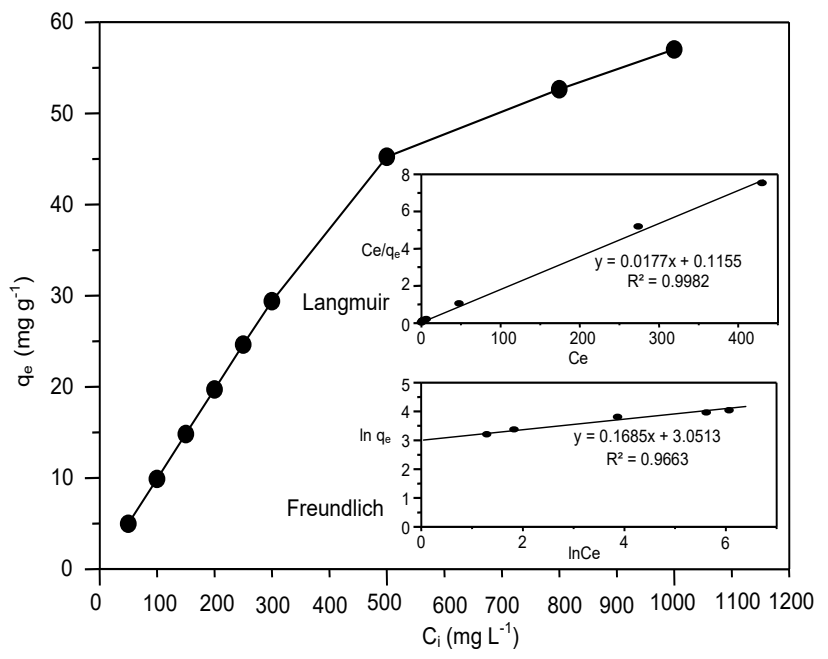

Figure 12. Langmuir and Freundlich adsorption isotherm. 
small and even constant. While the quantity of dye adsorbed per unit weight of adsorbent $\left(q_{t}\right)$ always increase until the value constant along with the increase of the dye initial concentration. The adsorption of methylene blue was tested in different $\mathrm{pH}$ medium. Figure 11 shows the effect of $\mathrm{pH}$ on the removal of methylene blue (100 mg.L $\mathrm{L}^{-1}$ dye concentration) using CFB-500(2) as adsorbent. The adsorption of methylene blue was quite consistent in the $\mathrm{pH}$ range of 4-10. However, the adsorption of dye in reaction medium with $\mathrm{pH} 2$ drops significantly. This indicates that the presence of excess $\mathrm{H}^{+}$ions in the solution became the competing ion to be adsorbed onto the active site of the surface of CFB-500(2).

\subsection{Adsorption Equilibrium Study}

The adsorption of methylene blue was checked using the Langmuir and the Freun-
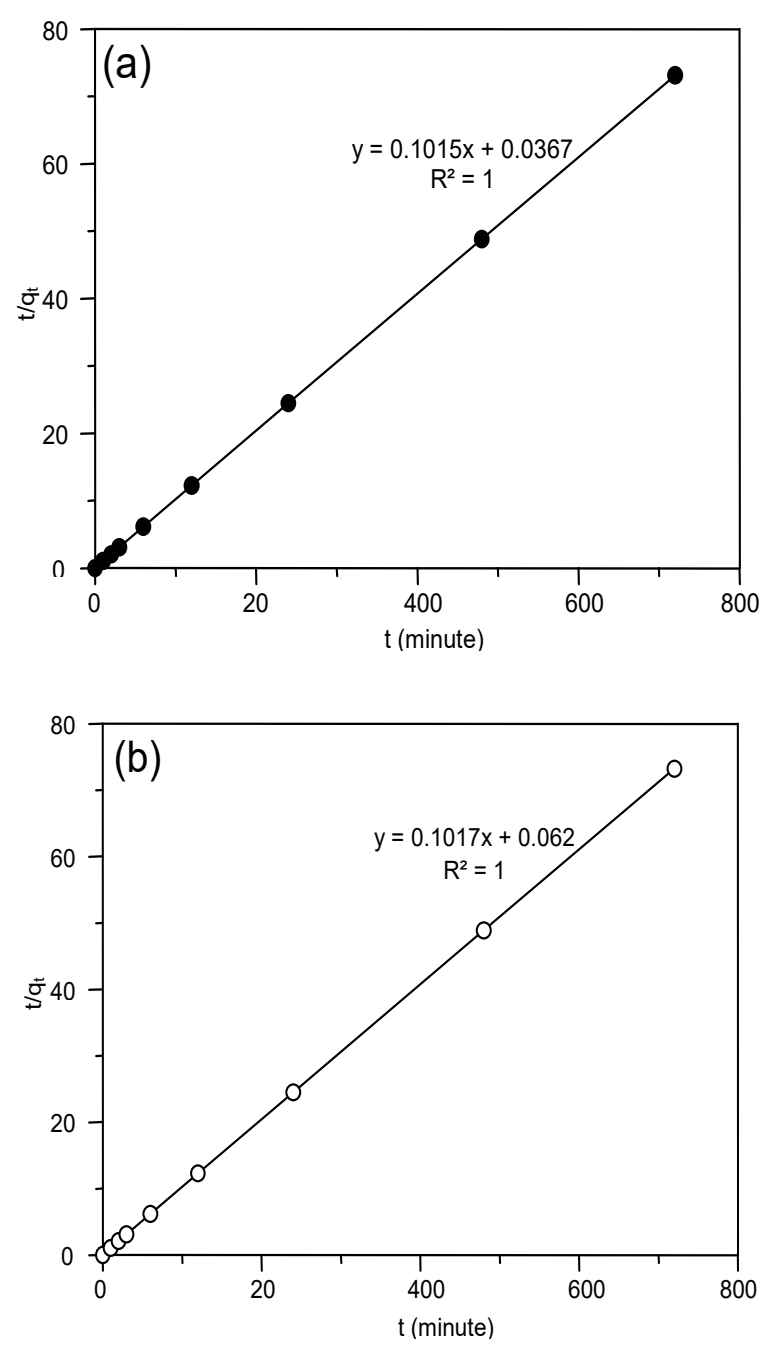

dlich adsorption models. The Langmuir adsorption model is assumed as the maximum adsorption corresponds to a saturated monolayer of solute onto the adsorbent surface. The adsorbate binding is treated as a chemical reaction between the adsorbate molecule and an empty site. Meanwhile, the Freundlich isotherm equation was correlated with heterogeneous surfaces and multi-layer adsorption $[12,15,20-22]$. The Langmuir equation is shown as equation (4) [21] and the Freundlich equation is followed as equations (5) and (6).

$$
\begin{aligned}
& \frac{C_{e}}{q_{e}}=\frac{C_{e}}{Q_{\max }}+\frac{1}{Q_{\max }^{b}} \\
& q_{e}=K_{F} C_{e}^{1 / n} \\
& \ln q_{e}=\ln K_{F}+(1 / n) \ln C_{e}
\end{aligned}
$$

where $C_{e}$ and $q_{e}$ are the residual dye concentration (mg.L $\mathrm{L}^{-1}$ ) and the number of the dye adsorbed on the sorbent at equilibrium (mg.g-1). $Q_{\max }$ is the maximum number of the dye per unit weight of sorbent and $b$ is the Langmuir adsorption equilibrium constant that related to the affinity between the sorbent and dye ions. On the other hands, $K_{F}$ is a measurement of the adsorption capacity and $n$ is the favorability of adsorption. If the value of $n>1$, it characterizes favorable adsorption condition.

Figure 12 shows the Langmuir and Freundlich adsorption isotherm. According to correlation coefficient, CFB-500(2) fits well to the Langmuir isotherm rather than Freundlich isotherm. The maximum adsorption capacity of methylene blue is calculated to be $56.49 \mathrm{mg}^{-{ }^{-1}}$.

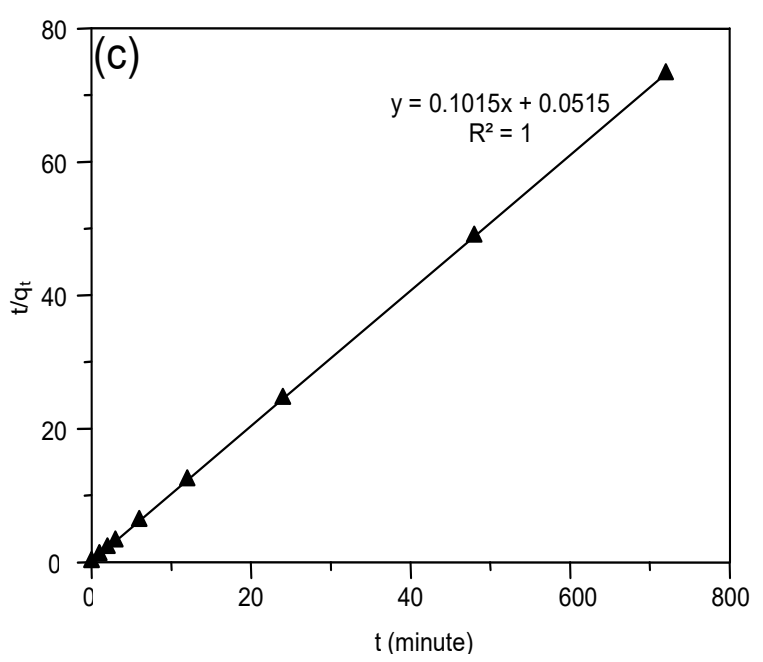

Figure 13. Pseudo-second-order kinetics plot for the adsorption of methylene blue dye. Conditions: (pH: 6.9, MB: $100 \mathrm{mg} \cdot \mathrm{L}^{-1}$, weight adsorbent: $250 \mathrm{mg}$, at (a) $30^{\circ} \mathrm{C}$, (b) $40^{\circ} \mathrm{C}$ and (c) $50{ }^{\circ} \mathrm{C}$ ). 
This is in-line with our previous finding that the removal of dye drops when the concentration of dye exceeds $500 \mathrm{mg} \cdot \mathrm{L}^{-1}$. This is because the dye molecules could only form monolayer at the surface site of CFB-500(2) through chemical binding. The excess dye molecules could not be removed since multilayer is not allowed. This is consistent with the large pore volume and surface area CFB-500(2).

\subsection{Adsorption Kinetics}

The adsorption kinetics of the adsorption of methylene blue onto carbon-containing hydroxyapatite was investigated using two kinetics models which are the pseudo-first-order model and pseudo-second-order model. The pseudofirst-order and pseudo-second-order models follow the first order Lagergren equation (8) $[23,24]$ and Ho's pseudo-second-order equation (9) $[12,15]$, respectively.

$$
\log \left(q_{e}-q_{t}\right)=\log q_{e, c a l}-\frac{k_{f}}{2.303} t
$$

Table 3. Rate Constant for the adsorption of methylene blue onto CFB-500(2) at different temperatures.

\begin{tabular}{ccccc}
\hline $\begin{array}{c}\text { Temp. } \\
\left({ }^{\circ} \mathrm{C}\right)\end{array}$ & $\begin{array}{c}q_{e, e x p} \\
\left(\mathrm{mg}^{-1}\right)\end{array}$ & $\begin{array}{c}q_{e, c a l} \\
\left(\mathrm{mg}^{-1} \mathrm{~g}^{-1}\right)\end{array}$ & $\begin{array}{c}k_{2} \\
\left(\mathrm{~g} \cdot \mathrm{mg}^{-1} \cdot \mathrm{h}^{-1}\right)\end{array}$ & $\mathrm{R}^{2}$ \\
\hline 30 & 9.844 & 9.852 & 0.280 & 1.000 \\
40 & 9.832 & 9.832 & 0.170 & 1.000 \\
50 & 9.845 & 9.852 & 0.200 & 1.000 \\
\hline
\end{tabular}

$$
\frac{t}{q_{t}}=\frac{1}{k_{2} q_{e, c a l}^{2}}+\frac{t}{q_{e, c a l}}
$$

where $q_{e}$ and $q_{t}$ are the amount of dye adsorbed per gram of adsorbent (mg.g $\left.{ }^{-1}\right)$ at time, $t$ in equilibrium. The adsorption of methylene blue by CFB-500(2) best fit into the pseudo-secondorder as shown in Figure 13. The correlation coefficient is found to be unity. As shown in Table 3 , the adsorption follows the pseudo-secondorder even at higher temperature of $50{ }^{\circ} \mathrm{C}$. The best fit to pseudo-second-order kinetics indicates that the rate-determining step may be a chemical adsorption which depends on the adsorbent and adsorbate [25-27].

\subsection{Determination of Thermodynamic Parame-} ters

The thermodynamic parameters include activation energy $\left(E_{a}\right)$, Gibbs free energy $(\Delta \mathrm{G})$, enthalpy $(\Delta \mathrm{H})$, and entropy $(\Delta \mathrm{S})$ was determined to find out the inherent energetic changes during the adsorption process of methylene blue onto the CFB-500(2). The Arrhenius equation was used to determine the activation energy $\left(E_{a}\right)$ and is expressed as equation (10) [20]:

$$
\ln k=\ln A-\frac{E_{a}}{R T}
$$

where $k$ is the rate constant $\left(k_{2}\right)$ which was obtained from pseudo-second-order models, $E_{a}$

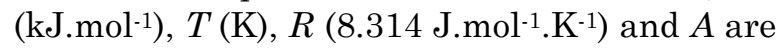

Table 4. Thermodynamic parameters

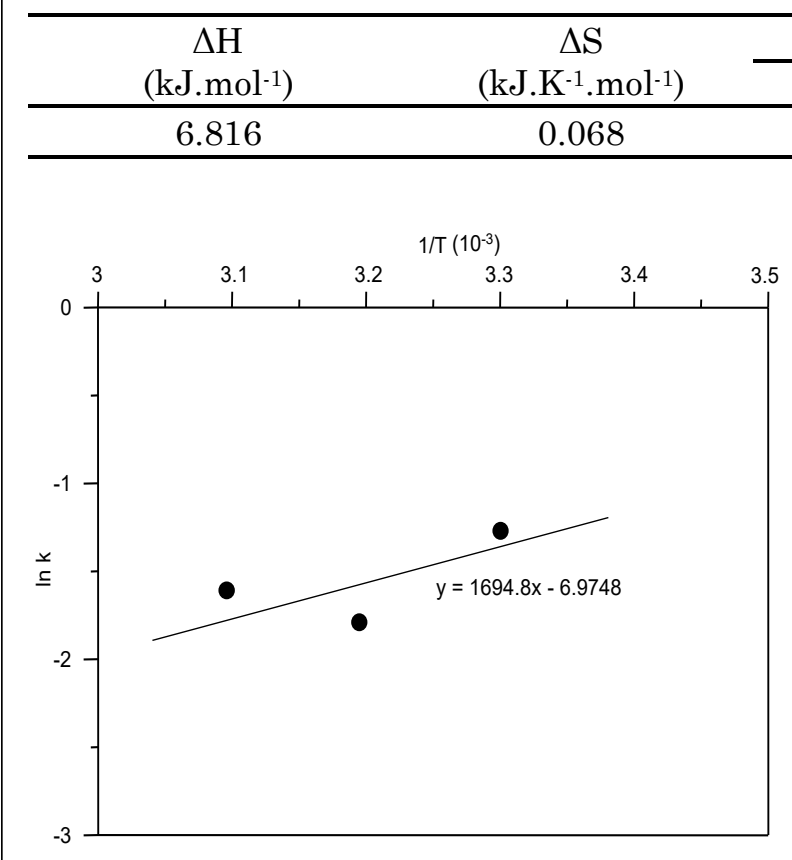

Figure 14. Plot ln $k$ versus $1 / T$.

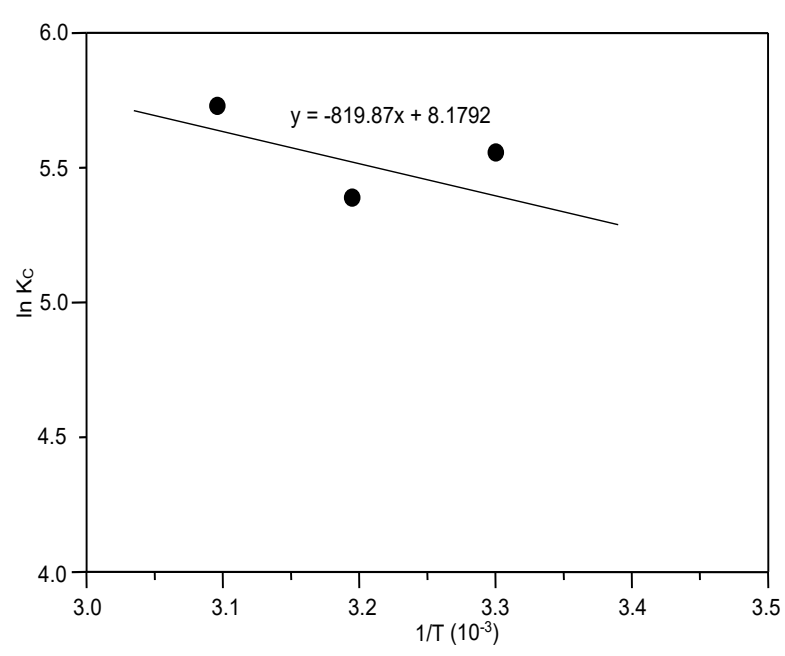

Figure 15. Plot $\ln K_{\mathrm{C}}$ versus $1 / T$. 
the Arrhenius activation energy, temperature of the adsorption medium, the gas constant and the Arrhenius factor, respectively. Figure 14 shows plot of $\ln k$ against $1 / T$ with slope and intercept were 1694.8 and -6.9748 , respectively. The value of activation energy $\left(E_{\alpha}\right)$ and the Arrhenius factor A were obtained -14.09 kJ.mol-1 and $9.35 \times 10^{-4}$, respectively. The Gibbs free energy $(\Delta \mathrm{G})$, enthalpy $(\Delta \mathrm{H})$, and entropy $(\Delta \mathrm{S})$ were calculated by using the following equations $[12,28]$ :

$$
\begin{aligned}
& K_{C}=\frac{C_{1}}{C_{2}} \\
& \Delta G^{0}=\Delta H^{0}-T \Delta S^{0} \\
& \Delta G^{0}=-R T \ln K_{C} \\
& \ln K_{C}=\frac{\Delta S^{0}}{R}-\frac{\Delta H^{0}}{R T}
\end{aligned}
$$

where $K_{C}$ is the equilibrium constant; $C_{1}$ is the quantity of methylene blue dye adsorbed on the adsorbent per liter of the solution at equilibrium time and $C_{2}$ is the concentration of methylene blue dye in the solution, respectively. $\Delta \mathrm{S}$ and $\Delta \mathrm{H}$ were calculated from the intercept and slope of the Van't Hoffs plots (ln $K_{C}$ against $1 / T$ ) as shown in Figure 15. The value of $\Delta \mathrm{H}$ and $\Delta \mathrm{S}$ were calculated to be $6816.4 \mathrm{~J}^{\mathrm{K}}{ }^{-1} \cdot \mathrm{mol}^{-1}$ and $0.068 \mathrm{~kJ} . \mathrm{K}^{-1} \cdot \mathrm{mol}^{-1}$, indicating the adsorption process of methylene blue onto carboncontaining hydroxyapatite is endothermic and random. The adsorption process of methylene blue onto carbon-containing hydroxyapatite is spontaneous as proven by the negative value of $\Delta \mathrm{G}$. The thermodynamic parameters of the adsorption process were listed in Table 4.

\section{Conclusions}

In this study, mesoporous carbon-containing hydroxyapatite has been synthesized from fish bone via simple calcination method. The optimum condition of synthesis was reached at calcination temperature $500{ }^{\circ} \mathrm{C}$ for $2 \mathrm{~h}$. The surface area and pore size of mesoporous carboncontaining hydroxyapatite were $158.8 \mathrm{~m}^{2} \cdot \mathrm{g}^{-1}$ and $44.1 \AA$. This material functions as an adsorbent for the methylene blue which is one of the major pollutants from dye industries. The adsorption process was done by batch system at room temperature with the adsorbent $(0.25 \mathrm{~g})$ and methylene blue dye solution $(25 \mathrm{~mL}, 100$ mg.L. $\left.{ }^{-1}\right)$. The adsorption of methylene blue onto the carbon-containing hydroxyapatite follows the Langmuir adsorption isotherm with the maximum adsorption capacity $56.49 \mathrm{mg} \cdot \mathrm{g}^{-1}$. The kinetic data for methylene blue fitted with a pseudo-second-order model with rate constant calculated 0.280 g.mg- ${ }^{-1} \cdot \mathrm{h}^{-1}$ at $30{ }^{\circ} \mathrm{C}$. The enthalpy $(\Delta \mathrm{H})$ of methylene blue adsorption was obtained as $6.814 \mathrm{~kJ} . \mathrm{mol}^{-1}$ and the adsorption process was endothermic. The activation energy $\left(E_{a}\right)$ of methylene blue adsorption was determined as $-14.09 \mathrm{~kJ} \mathrm{~mol}^{-1}$. The adsorption of methylene blue onto the carbon-containing hydroxyapatite is spontaneous as predicted from the Gibbs free energy $(\Delta \mathrm{G})$ as -13.80 kJ.mol ${ }^{-1}$ at $30{ }^{\circ} \mathrm{C}$. As conclusion, carboncontaining hydroxyapatite synthesized from fish bone can be a potential low-cost adsorbent for the removal of methylene blue.

\section{Acknowledgements}

The author is grateful to the funding from government by Ministry of Research, Technology, and Higher Education Grant of Republic of Indonesia.

\section{References}

[1] Peng, Q., Yu, F., Huang, B., Huang, Y. (2017). Carbon-containing bone hydroxyapatite obtained from tuna fish bone with high adsorption performance for Congo red. Royal Soc. Chem. 7: 26968-26973.

[2] Kumar, P.S., Ramalingam, S., Sathishkumar, K. (2011). Removal of methylene blue dye from aqueous solution by activated carbon prepared from cashew nut shell as a new lowcost adsorbent. Korean J. Chem. Eng. 28(1): 149-155.

[3] Pavan, F.A., Mazzocato, A.C., Gushikem, Y. (2008). Removal of methylene blue dye from aqueous solution by adsorption using yellow passion fruit peel as adsorbent. Bioresour. Technol. 99: 3162-3165.

[4] Yi, J.-Z., Zhang, L.-M. (2008). Removal of methylene blue dye from aqueous solution by adsorption onto sodium humate/ polycrylamide/clay hybrid hydrogels. Bioresour. Technol. 99: 2182-2186.

[5] Wanyonyi, W.C., Onyari, J.M., Shiundu, P.M. (2013). Adsorption of methylene blue dye from aqueous solution using Eichhornia crassipes. Bull. Environ. Contam. Toxicol. 91 (3): 362- 366.

[6] Crini, G.G. (2006). Non-conventional low-cost adsorbents for dye removal: a review. Bioresour. Technol., 97: 1061-1085

[7] Patel, S., Han, J., Qiu, W., Gao, W. (2015). Synthesis and characterisation of mesoporous bone char obtained by pyrolysis of animal bones, for environmental application. J. Environ. Chem. Eng. 3: 2368-2377. 
[8] Sikaily, A.E., Khaled, A., Nemr, A.E., Abdelwahab, O. (2006). Removal of Methylene Blue from aqueous solution by marine green alga Ulva lactuca. Chem. Ecol. 22: 149-157.

[9] Kumar, P.S., Abhinayaa, R.V., Lashmia, K.G., Arthia, V., Pavithraa, R., Sathyaselvabalab, V., Kirupha S.D., Sivanesan S. (2011). Adsorption of methylene blue dye from aqueous solution by agricultural waste: equilibrium, thermodynamics, kinetics, mechanism and process design. Colloid J. 73(5): 651-657.

[10] Gao, J.-J., Qin, Y.-B., Zhou, T., Cao, D.-B., Xu, P., Hochstetter, D., Wang, Y.-F. (2013). Adsorption of methylene blue onto activated carbon produced from tea (Camellia sinensis L.) seed shells: kinetics, equilibrium, and thermodynamics studies. J. Zhejiang Univ-Sci. B (Biomed \& Biotechnol), 14(7): 650-658.

[11] Rashidzadeh, A., Olad, A., Salari, D. (2015). The Effective Removal of Methylene Blue Dye from Aqueous Solution by NaAlg-gPoly(acrylic acid-co-acryl amide/Clinoptilolite hydrogel Nanocomposite. Fibers Polym. 16(2): 354-362.

[12] Errais, E., Duplay, J., Darragi, F., M'Rabet, I., Aubert, A., Huber, F., Morvan, G. (2011). Efficient anionic dye adsorption on natural untreated clay: Kinetic study and thermodynamic parameters. Desalination, 275: 74-81.

[13] Gil, A., Assis, F.C.C., Albeniz, S., Korili, S.A. (2011). Removal of dyes from wastewaters by adsorption on pillared clays. Chem. Eng. J. 168: 1032-1040.

[14] Zawahry, M.M.E., Kamel, M.M. (2004). Removal of azo and anthraquinone dyes from aqueous solutions by Eichhornia crassipes. Water Res. 38: 2967-2972, doi:10.1016/S00431354(01)00526-7.

[15] Wanyonyi, W.C., Onyari, J.M., Shiundu, P.M. (2014). Adsorption of congo red dye from aqueous solution using roots of Eichhornia crassipes: kinetic and equilibrium studies $E n$ ergy Procedia, 50: 862-869.

[16] Peng, Q., Yu, F., Huang, B., Huang, Y. (2017). Carbon-containing bone hydroxyapatite obtained from tuna fish bone with high adsorption performace for Congo red. The Royal Soc. Chem. 17: 26968-26973.

[17] Giri, A.K., Patel, R., mandal, S. (2012). Removal of $\mathrm{Cr}(\mathrm{VI})$ from aqueous solution by Eichhornia crassipes root biomass-derived activated carbon. Chem. Eng. J. 185-186: 71-81.
[18] Wang, L. (2012). Application of activated carbon derived from 'waste' bamboo culms for the adsorption of azo disperse dye: kinetic, equilibrium and thermodynamic studies. $J$. Environ. Manage. 102: 79 - 87.

[19] Lim, H.K., Teng, T.T., Ibrahim, M.H., Ahmad, A., Chee, H.T. (2012). Adsorption and removal of zinc(II) from aqueous solution using powdered fish bones. APCBEE Procedia, 1: $96-102$.

[20] Kizilkaya, B., Tekinay, A.A., Dilgin, Y. (2010). Adsorption and removal of $\mathrm{Cu}$ (II) ions from aqueous solution using pretreated fish bones. Desalination, 264(1-2): 37-47.

[21] Karaoglu, M.H., Dogan, M., Alkan, M. (2010). Removal of reactive blue 221 by kaolinite from aqueous solution. Ind. Eng. Chem. Res., 49: 1534-1540.

[22] Alkan, M., Celikapa, S., Demirbas, O., Dogan, M. (2005). Removal of reactive blue 221 and acid blue 62 anionic dyes from aqueous solution by sepiolite. Dyes and Pigments, 65: 251259.

[23] Sinha, S., Pandey, K., Mohan, D., Singh, K.P. (2003). Removal of fluoride from aqueous solutions by Eichhornia crassipes biomass and its carbonized form. Ind. Eng. Chem. Res., 42: 6911-6918

[24] Mohanty, K., Jha, M., Meikap, B.C., Biswas, M.N. (2006). Biosorption of $\mathrm{Cr}(\mathrm{VI})$ from aqueous solutions by Eichhornia crassipes. Chem. Eng. J. 117: 71-77

[25] Ho, Y.-S. (2006). Review of second-order models for adsorption systems. J. Hazard Mater. 136(3): 681-689.

[26] Ho, Y.-S., McKay, G. (1999). Pseudo-second order model for sorption processes. Process Biochem. 34(5): 451-465.

[27] Simonin, J.-P. (2016). On the comparison of pseudo-first order and pseudo-second order rate laws in the modeling of adsorption kinetics. Chem. Eng. J. 300: 254-263.

[28] Acemioglu, B., Almay, M.H. (2001). Equilibrium studies on adsorption of $\mathrm{Cu}(\mathrm{II})$ from aqueous solution onto cellulose. J. Colloid Interface Sci. 243: 81-84. 